Original Article

\title{
Users' Satisfaction with Assistive Devices in South Korea
}

\author{
SAng-HeOn LeE, OT, PhD ${ }^{1)}$ \\ ${ }^{1)}$ Department of Occupational Therapy, College of Medical Science, Soonchunhyang University: 646 \\ Eupnae-ri, Shinchang-myeon, Asan-si, Chungnam 336-745, Republic of Korea
}

\begin{abstract}
Purpose] The objective of this study was to determine users' satisfaction with assistive devices, and their serviceability and effectiveness. [Methods] A random sample of 138 users participated in this study. The Korean-Quebec User Evaluation of Satisfaction with Assistive Technology 2.0 and an additional questionnaire were used for data collection. Data were analyzed by using descriptive statistics. [Results] Overall client satisfaction was high. Respondents most commonly reported use of their device for "personal activities of daily living" and "mobility", and considered engagement in "activities of daily living", and "social participation" to be most desirable, respectively. [Conclusion] This study will provide rehabilitation professionals with valuable information about client satisfaction with assistive devices.
\end{abstract}

Key words: Assistive devices, K-QUEST 2.0, Satisfaction

(This article was submitted Sep. 10, 2013, and was accepted Oct 24, 2013)

\section{INTRODUCTION}

Assistive Technologies (ATs), defined as "electrical or mechanical devices designed to help people recover movement", have demonstrated clinical benefits in upper-limb stroke rehabilitation ${ }^{1)}$. AT has the potential to reduce the effects of occupational performance limitations on everyday life activities by facilitating and enhancing work performance and social interactions ${ }^{2,3}$. An assistive device may compensate for decreased or lost physical function and ability to manage the activities of daily life, increase or maintain function and ability, and prevent future loss of function and ability. Assistive technologies may provide; an increased intensity of therapy without a corresponding increase in clinical contact time, motivating relevant activities, either functional or impairment based, and can be used outside the hospital ${ }^{1)}$. Also, a health-care professional must provide an assistive technology intervention that enhances the user's self-reliance while maintaining quality in a costeffective manner ${ }^{4}$.

The imperative of adopting the philosophy and methods of evidence-based practice confronts many fields of human service, assistive technologies among them ${ }^{5}$. Therapists are under increasing pressure to base their practices more firmly on "evidence" and to verify the effects of certain interventions. Evidence-based practice should form the basis of all rehabilitation, including the application of assistive

Corresponding author. Sang-Heon Lee (E-mail: sangheon@ sch.ac.kr)

C2014 The Society of Physical Therapy Science. Published by IPEC Inc. This is an open-access article distributed under the terms of the Creative Commons Attribution Non-Commercial No Derivatives (by-ncnd) License $<$ http://creativecommons.org/licenses/by-nc-nd/3.0/> devices. Very little data is available in this area ${ }^{6}$. An empirical and useful evidence base for the outcomes of assistive device use requires research based on relevant and valid evaluation tools as well as a client-centered working model. This is a challenge, as few measures are available that target the measurement of assistive device use outcomes ${ }^{7)}$.

The Quebec User Evaluation of Satisfaction with Assistive Technology (QUEST) was developed by an occupational therapist in Canada during the 1980s. It can be either self-administered or completed with the help of an evaluator $^{8)}$. It is designed to evaluate a person's satisfaction with his or her assistive device and can be used with adolescents, adults, and elderly people who have acquired an assistive device because of physical or sensory impairments. QUEST 2.0 has been amended to focus on satisfaction with specific features of an assistive device as well as certain characteristics of services related to the device ${ }^{9}$.

The selection and clinical evaluation of any assistive device should involve the client ${ }^{10)}$. It is important to analyze the benefits and limitations of a device from the user's point of view. This information supports policy makers in the identification of optimal health-care procedures in this field ${ }^{7}$. Despite the increasing need for, interest in, and use of assistive devices among clients, no study has analyzed the outcomes of these prescriptions in South Korea.

The aim of this study was to evaluate client satisfaction concerning products and service related to assistive devices and their serviceability and usefulness.

\section{PARTICIPANTS AND METHODS}

A cross-sectional follow-up study design was used. Two assistive device centers in Seoul, South Korea, participated. The regional councils for the areas in which the centers 
were locate decided the selection of assistive devices available for prescription. Assistive devices were distributed through these centers.

A postal package containing questionnaires was sent to a random sample of 448 users of assistive devices during the winter of 2011. One questionnaire included items concerning demographic data and questions about usage as well as the user's opinion of how the device had influenced activity engagement. The other questionnaire was a Korean-Quebec User Evaluation of Satisfaction with Assistive Technology (K-QUEST 2.0) form. User sampling was performed from the regional councils' registries of all prescriptions for assistive devices in 2011. An addressed reply envelope and a letter explaining the objectives of the study were also provided.

The K-QUEST 2.0 scale investigates two dimensions: satisfaction with the device (eight items) and satisfaction with the assistive device service (four items) ${ }^{8}$. Evaluation related to the characteristics of the device includes user satisfaction with "dimensions", "weight", "adjustment", "safety", "durability", "simplicity of use", "comfort", and "effectiveness." Each item is scored on a 5-point satisfaction scale, where 1 denotes "not satisfied at all" and 5 denotes "very satisfied". Evaluation associated with the related services includes user satisfaction with "service delivery", "repairs and servicing", "professional services", and "followup". The same 5-point satisfaction scale as above is used to rate these items. A checklist with the 12 satisfaction items is presented on the QUEST 2.0 form, and the user is asked to select the three most important items. The psychometric properties of QUEST 2.0 have been validated in several studies $^{11-14)}$.

Data from both questionnaires were analyzed by using descriptive statistics. This study was approved by the Institutional Review Board of Soonchunhyang University. All participants provided informed consent before participating.

\section{RESULTS}

A total of $142(72 \%)$ users out of 448 originally queried returned the questionnaires. Included in the data analysis are 138 users with several types of assistive devices. In all, 75 men and 63 women participated (Table 1).

Participants mainly used assistive devices for mobility or seating and positioning. User satisfaction levels for both assistive device (AD) and assistive device service (ADS) were high, as illustrated in Table 2. A majority of users marked the ratings "more or less satisfied" or "quite satisfied" for most items. Satisfaction ratings for "weight" and "repairs \& services" were the lowest for the AD and ADS dimensions, respectively. "Ease of use" and "durability" in the AD dimension and "service delivery" in the ADS were deemed the three most important factors.

Participants used their assistive devices for "personal activities of daily living" ( $\mathrm{n}=79 / 209,37.80 \%)$, "mobility" ( $\mathrm{n}=72 / 209,34.45 \%)$, "education" ( $\mathrm{n}=12 / 209,5.74 \%)$, "cultural, leisure, and sports activity" ( $\mathrm{n}=8 / 209,3.83 \%)$, "communication" ( $\mathrm{n}=5 / 209,2.39 \%)$, "religious and spiri-
Table 1. Demographic data of responding users of assistive devices $(n=138)$

\begin{tabular}{lcc}
\hline Gender n (\%) & Male & $75(54.3)$ \\
& Female & $63(45.7)$ \\
\hline & Under ten years & $28(20.3)$ \\
& $10-19$ years & $31(22.5)$ \\
& $20-29$ years & $25(18.1)$ \\
Age n (\%) & $30-39$ years & $16(11.6)$ \\
& $40-49$ years & $11(8.0)$ \\
& $50-59$ years & $16(11.6)$ \\
& $60-69$ years & $8(5.8)$ \\
& Over 70 years & $3(2.2)$ \\
\hline Disability & First & $119(86.2)$ \\
severity n (\%) & Second & $13(9.4)$ \\
& Third & $6(4.4)$ \\
& Other & $67(48.6)$ \\
\hline Residence $\mathrm{n}(\%)$ & Apartment & $67(48.6)$ \\
& Single family & $15(10.9)$ \\
& Multi-family & $20(14.5)$ \\
& Other & $36(26.1)$ \\
\hline Highest level of & None & $23(16.7)$ \\
education $\mathrm{n}(\%)$ & Middle school & $23(16.7)$ \\
& High school & $34(24.6)$ \\
& College & $19(13.8)$ \\
& Graduate school & $5(3.6)$ \\
\hline
\end{tabular}

tual activities" ( $n=5 / 239,2.09 \%)$, and "work" ( $n=4 / 209$, $1.91 \%$ ). Users expressed difficulty engaging in activities (n $=85 / 135,62.96 \%$ ). The most desired activities to engage in and most difficult to perform were "activities of daily living" followed by "social participation" (Table 3).

\section{DISCUSSION}

Assistive devices improve the ability of the user to perform activities of daily living ${ }^{15,16)}$. They also decrease users' dependence on human assistance, especially assistance from informal caregivers, that is, friends, family, and community members who provide unpaid assistance to ill or disabled recipients ${ }^{17)}$.

A hallmark of evidence-based practice is a commitment to addressing consumers' goals ${ }^{5)}$. Evaluation of success must be based on evidence obtained from the user's point of view. For the AT field, this entails an emphasis on outcomes research that speaks to the contributions that devices and related services make to users' daily lives ${ }^{5}$.

This is the first experimental study to examine the impact of assistive technology-focused interventions on users' satisfaction with and the usefulness of assistive devices in South Korea. The results from K-QUEST 2.0 showed that the overall satisfaction for both AD and ADS was high. The level of satisfaction with "weight" and "adjustments" in the AD dimension and "repair \& services" in the ADS dimension were relatively lower than with other categories. Users 
Table 2. Item by item analysis of aspects affecting user satisfaction and their relative importance to users of assistive devices

\begin{tabular}{|c|c|c|c|c|c|c|c|}
\hline \multirow[b]{2}{*}{ Items } & & \multicolumn{5}{|c|}{ Satisfaction $^{*}(\mathrm{~N}=138)$} & \multirow{2}{*}{$\begin{array}{l}\text { Most impor- } \\
\text { tant items*, }\end{array}$} \\
\hline & & $\begin{array}{c}\text { Not satisfied } \\
\text { at all }\end{array}$ & $\begin{array}{l}\text { Not very } \\
\text { satisfied }\end{array}$ & $\begin{array}{c}\text { More or less } \\
\text { satisfied }\end{array}$ & $\begin{array}{c}\text { Quite } \\
\text { Satisfied }\end{array}$ & $\begin{array}{c}\text { Very } \\
\text { satisfied }\end{array}$ & \\
\hline \multirow{8}{*}{$\begin{array}{l}\text { Assistive } \\
\text { device }\end{array}$} & Dimensions & $2(1.4)$ & $20(14.5)$ & $39(28.3)$ & $42(30.4)$ & $35(25.4)$ & $35(25.7)$ \\
\hline & Weight & $13(9.4)$ & $26(18.8)$ & $40(29.0)$ & $36(26.1)$ & $23(16.7)$ & $23(16.7)$ \\
\hline & Adjustment & $9(6.5)$ & $24(17.4)$ & $35(25.4)$ & $40(29.0)$ & $30(21.7)$ & $30(21.7)$ \\
\hline & Safety & $2(1.4)$ & $17(12.3)$ & $40(29.0)$ & $44(31.9)$ & $35(25.4)$ & $35(25.4)$ \\
\hline & Durability & $6(4.3)$ & $15(10.9)$ & $34(24.6)$ & $43(31.2)$ & $40(29.0)$ & $40(29.0)$ \\
\hline & Ease of use & $5(3.6)$ & $12(8.7)$ & $37(26.8)$ & $41(29.7)$ & $43(31.2)$ & $43(31.2)$ \\
\hline & Comport & $5(3.6)$ & $16(11.6)$ & $42(30.4)$ & $47(34.1)$ & $28(20.3)$ & $28(21.3)$ \\
\hline & Effectiveness & $3(2.2)$ & $5(3.6)$ & $40(29.0)$ & $51(37.0)$ & $37(26.8)$ & $37(26.8)$ \\
\hline \multirow{4}{*}{$\begin{array}{l}\text { Assistive } \\
\text { device } \\
\text { service }\end{array}$} & Service delivery & $12(8.7)$ & $18(13.0)$ & $36(26.1)$ & $31(22.5)$ & $40(29.0)$ & $40(29.0)$ \\
\hline & Repairs \& services & $14(10.1)$ & $33(23.9)$ & $35(25.4)$ & $26(18.8)$ & $30(21.7)$ & $30(21.7)$ \\
\hline & Professional Service & $7(5.1)$ & $26(18.8)$ & $41(29.7)$ & $28(20.3)$ & $36(26.1)$ & $36(26.1)$ \\
\hline & Follow up & 15 (10.9) & $22(15.9)$ & $46(33.3)$ & 27 (19.6) & $28(20.3)$ & $28(20.3)$ \\
\hline
\end{tabular}

$* \mathrm{n}(\%) ; * *$ multiple responses

Table 3. Comparison of user ratings of activity difficulty and desirability

\begin{tabular}{lcc}
\hline & $\begin{array}{c}\text { Activity found } \\
\text { difficult } \\
\text { to engage in }^{*, * *}\end{array}$ & $\begin{array}{c}\text { Activity } \\
\text { desirable } \\
\text { to engage in }{ }^{* * *}\end{array}$ \\
\hline Activities of daily livings & $96(28.1)$ & $134(30.2)$ \\
Rest and sleep & $19(5.6)$ & $16(3.6)$ \\
Education & $45(13.2)$ & $57(12.9)$ \\
Work & $37(10.8)$ & $39(8.8)$ \\
Play & $43(12.6)$ & $69(15.6)$ \\
Leisure & $35(10.2)$ & $58(13.1)$ \\
Social participation & $67(19.6)$ & $70(15.8)$ \\
\hline
\end{tabular}

$* \mathrm{n}(\%) ; * *$ multiple responses

most often considered "ease of use" and "durability" in the AD dimension and "service delivery" in the ADS dimension to be the most important items. Therefore, health-care providers need to have information about various types of assistive devices to enable them to educate users on how to utilize and adapt their prescribed devices, and need to provide follow-up service.

Overall, K-QUEST 2.0 showed that satisfaction with ADS was lower than with the AD. The two device centers in Seoul, South Korea, began to prescribe assistive devices a few years ago. Similar results may be found in other centers that have opened recently outside of Seoul. One plausible explanation for obtaining lower satisfaction with ADS is that user-centered assistive device delivery systems have not been established. Professional services and support should be based on individual needs and promote community participation ${ }^{18}$. Only a few suppliers provide assistive devices for many consumers without full consideration of needs, body fit, and follow-up service ${ }^{19)}$. Assistive device suppliers and centers therefore need to develop effective assistive device delivery models for users.

Determining the outcomes of assistive device interven- tions designed to improve participation of users provides critical feedback to clients, therapists, and agencies that provide funding for equipment ${ }^{20}$ ). As social participation reflects the fulfillment of personal roles ${ }^{21)}$, appraisal of participation outcomes for each individual is critical ${ }^{22}$. Most participants use assistive devices to improve their "personal activities of daily living" and "mobility". Nevertheless, they express difficulty in engaging in both "activities of daily living" and "social participation" while declaring a desire to perform these activities. These results indicate that continuous social and economic support derived from the users' points of view must be provided to secure basic activities and social engagement.

\section{ACKNOWLEDGEMENT}

This work was supported by the Soonchunhyang University Research Fund.

\section{REFERENCES}

1) Demain S, Burridge J, Ellis-Hill C, et al.: Assistive technologies after stroke: self-management or fending for yourself? A focus group study. BMC Health Serv Res, 2013, 13: 334. [Medline] [CrossRef]

2) Edyburn D: 2007. Re-examining the role of assistive technology in learning. Closing the Gap 25:5. https://pantherfile.uwm.edu/edyburn/www/ ATinDepth.pdf (Accessed Apr. 16, 2011)

3) Smith RO: Measuring the outcomes of assistive technology: challenge and innovation. Assist Technol, 1996, 8: 71-81. [Medline] [CrossRef]

4) Yeomans SG: The clinical application of outcomes assessment. Stamford: Appleton \& Lange, 2000.

5) Fuhrer MJ, Jutai JW, Scherer MJ et al.: A framework for the conceptual modelling of assistive technology device outcomes. Disabil Rehabil, 2003, 25: $1243-1251$.

6) Fuhrer M: Assistive technology outcomes research: Impressions of an interested newcomer. Paper presented at the International Conference on Outcome Assessment in Assistive Technology, Norway: Oslo, 1999. http:// www.utoronto.ca/atrc/reference/atoutcomes/newcomer/index (Accessed Jul. 19, 2005)

7) Samuelsson K, Wressle E: User satisfaction with mobility assistive devices: an important element in the rehabilitation process. Disabil Rehabil, 2008, 30: 551-558. [Medline] [CrossRef]

8) Lee S, Park S, Jung B: Korean translation and psychometric properties of 
Quebec user evaluation of satisfaction assistive technology 2.0. J Kor Acad Ind Coop, 2013, 14: 3284-3292.

9) Demers L, Weiss-Lambrou R, Ska B: Development of the Quebec Use Evaluation of Satisfaction with assistive Technology (QUEST). Assist Technol, 1996, 8: 3-13. [Medline] [CrossRef]

10) Caligari M, Godi $M$, Guglielmetti $S$, et al.: Eye tracking communication devices in amyotrophic lateral sclerosis: impact on disability and quality of life, 2013, Early Online: 1-7.

11) Wessels RD, De Witte LP: Reliability and validity of the Dutch version of QUEST 2.0 with users of various types of assistive devices. Disabil Rehabil, 2003, 25: 267-272. [Medline] [CrossRef]

12) Demers L, Monette M, Lapierre $Y$, et al.: Reliability, validity, and applicability of the Quebec User Evaluation of Satisfaction with assistive Technology (QUEST 2.0) for adults with multiple sclerosis. Disabil Rehabil, 2002, 24: 21-30. [Medline] [CrossRef]

13) Demers L, Wessels R, Weiss-Lambrou R, et al.: Key dimensions of client satisfaction with assistive technology: a cross-validation of a Canadian measure in The Netherlands. J Rehabil Med, 2001, 33: 187-191. [Medline] [CrossRef]

14) Demers L, Weiss-Lambrou R, Ska B: Item analysis of the Quebec User Evaluation of Satisfaction with Assistive Technology (QUEST). Assist Technol, 2000, 12: 96-105. [Medline] [CrossRef]

15) Mann WC, Ottenbacher KJ, Fraas L, et al.: Effectiveness of assistive technology and environmental interventions in maintaining independence and reducing home care costs for the frail elderly. A randomized controlled trial. Arch Fam Med, 1999, 8: 210-217. [Medline] [CrossRef]

16) Agree EM, Freedman VA, Sengupta M: Factors influencing the use of mobility technology in community-based long-term care. J Aging Health, 2004, 16: 267-307. [Medline] [CrossRef]

17) Mortenson W, Demers L, Fuhrer M, et al.: Effects of an assistive technology intervention on older adults with disabilities and their informal caregivers: an exploratory randomized controlled trial. Am J Phys Med Rehabil, 2013, 92: 297-306. [Medline] [CrossRef]

18) Lindstedt $\mathrm{H}, \mathrm{Umb}-\mathrm{Carlsson} \mathrm{O}$ : Cognitive assistive technology and professional support in everyday life for adults with ADHD. Disabil Rehabil Assist Technol, 2013, 8: 402-408. [Medline] [CrossRef]

19) : Korean translation and psychometric properties of Quebec User evaluation of Satisfaction Assistive Technology 2.0. JKAIS, 2013, 14: 3284 3292 .

20) Miller WC, Garden J, Mortenson WB: Measurement properties of the wheelchair outcome measure in individuals with spinal cord injury. Spinal Cord, 2011, 49: 995-1000. [Medline] [CrossRef]

21) Cardol M, de Haan RJ, de Jong BA, et al.: Psychometric properties of the impact on participation and autonomy questionnaire. Arch Phys Med Rehabil, 2001, 82: 210-216. [Medline] [CrossRef]

22) Noreau L, Fougeyrollas P, Post M, et al.: Participation after spinal cord injury: the evolution of conceptualization and measurement. J Neurol Phys Ther, 2005, 29: 147-156. [Medline] [CrossRef] 